\title{
EXPERIÊNCIAS DO RACISMO PERCEBIDAS NAS PRÁTICAS DE CUIDADOS EM PESSOAS COM DOENÇA FALCIFORME NA REDE DE ATENÇÃO À SAÚDE
}

\author{
Kevin Góes Lôbo'; Edna Maria de Araújo²; Aline Silva Gomes Xavier ${ }^{3}$; Kayque Neves \\ da Silva ${ }^{4}$; Jackeline Sena Nunes ${ }^{5}$ \\ 1. Bolsista Probic/Uefs, Graduando em Medicina, Universidade Estadual de Feira de Santana, e-mail: \\ keevinlobo@hotmail.com \\ 2. Orientador, Departamento de Saúde, Universidade Estadual de Feira de Santana, e-mail: \\ ednakam.@gmail.com \\ 3. Coparticipante, Departamento de Saúde, Universidade Estadual de Feira de Santana, e-mail: \\ asgx80@gmail.com \\ 4. Coparticipante, Graduando em Medicina, Universidade Estadual de Feira de Santana, e-mail: \\ kayque-sn@hotmail.com \\ 5. Coparticipante, Graduando em Medicina, Universidade Estadual de Feira de Santana, e-mail: \\ Kelmed2@gmail.com
}

PALAVRAS-CHAVE: Doença falciforme, saúde, racismo.

\section{INTRODUÇÃO}

O racismo, seus efeitos e mecanismos de reprodução têm impactado de modo expressivo e perverso a sociedade brasileira. As mazelas da escravidão se disseminaram, criaram raízes e se transmutaram a ponto de funcionar como meio eficiente de segregação em tempos de liberdade, alimentado e disfarçado pelo mito da democracia racial (SOARES, 2014).

A discriminação racial tem sido cada vez mais reconhecida como determinante das iniquidades étnico-raciais em saúde, com evidente crescimento e forte associação entre discriminação racial e efeitos na saúde de adultos, jovens e crianças, tanto no âmbito nacional quando internacional (PRIEST et al. 2013; BASTOS, FAERSTEIN, 2012).

Pela sua alta prevalência, a DF configura-se como importante questão de saúde pública no Brasil (Brasil, 2001), somado ao fato do racismo ser velado nas redes de saúde e cuidado às pessoas adoecidas, como o exemplo das pessoas com DF, ressalta-se a importância de estudos voltados para o tema. Com isso, esse estudo tem como objeto de estudo as experiências de racismo percebidas pelas pessoas com DF na rede de atenção à saúde e, dessa forma, suscitou-se a seguinte questão norteadora: Como as pessoas com doença falciforme percebem o racismo nas práticas de cuidado à saúde?

O objetivo geral desse estudo foi compreender as experiências do racismo percebidas nas práticas de cuidados em pessoas com DF na rede de atenção à saúde.

Nesse tocante, a pesquisa revela-se fundamental para, a identificação de experiências racistas pelos usuários dos centros de referências que cuidam das pessoas com Doença falciforme (DF), podendo assim gerar reflexões e enfrentamentos dessas mazelas discriminatórias, e, assim, melhorar o atendimento/cuidado à essas pessoas e interferir positivamente na qualidade vida das mesmas.

\section{MATERIAL E MÉTODOS (ou equivalente)}

Trata-se de um estudo de abordagem qualitativa, no plano de pesquisa exploratória, realizado no Centro de Referência à Pessoa com Doença Falciforme, localizado no bairro Cidade Nova em Feira de Santana - Bahia e na Associação Baiana dos Portadores de Doença Falciforme em Salvador - Bahia. Os sujeitos deste estudo foram mulheres e homens jovens e adultos, com doença falciforme cadastrados em ambas as instituições.

Este estudo está vinculado ao projeto matriz "Avaliação da Atenção à Saúde da População Negra e a Intersecção do Racismo Sobre as Práticas de Cuidado em Estados do 
Nordeste e do Sudeste brasileiro" registrado no Sistema Nacional de Ética na Pesquisa (SISNEP) e aprovado pela Comissão de Ética na Pesquisa (CEP) da Universidade Estadual de Feira de Santana (UEFS), através do parecer de No 1423346.

Foram adotadas todas as recomendações do Conselho Nacional de Pesquisa (CONEP), segundo a resolução $\mathrm{n}^{\mathrm{o}} 466$ de 12 de dezembro de 2012. Para a coleta de dados, utilizou-se a técnica de entrevista semiestruturada, utilizando um roteiro de entrevista para caracterização dos participantes, um roteiro composto por questões abertas sobre a percepção dos cuidados à saúde dado a pessoa com doença falciforme. As falas foram submetidas à análise de conteúdo, conforme proposto por (Bardin, 2009).

\section{RESULTADOS E/OU DISCUSSÃO (ou Análise e discussão dos resultados)}

Foram estudadas dez (10) pessoas com diagnóstico de DF. A média de idade dos entrevistados foi de 38,5 anos. Residem nas cidades de Feira de Santana e Salvador seis dos dez entrevistados.

Em relação a cor, quatro (4) se declararam da cor preta, seis (6) afirmam ser pardos. Quanto ao estado civil 5 são solteiros. Em relação ao grau de escolaridade três (3) não concluíram o ensino fundamental, quatro (4) concluíram o ensino médio, assim como também apenas um concluiu o ensino superior. Com relação à ocupação, cinco (5) dos entrevistados afirmaram não possuir trabalho e que a DF e não permite a realização de uma atividade laboral.

As religiões de predominância foi a católica cinco (5) adeptos. Em relação ao tipo da doença falciforme, nove (9) participantes são HbSS, um (1) HbSC. As crises álgicas estavam presentes em sete (7) dos entrevistados.

Após a análise das entrevistas foi possível compreender a partir de algumas categorias, quais as experiências e a percepção do cuidado à saúde das pessoas com DF.

\subsection{Categoria Temática 1 - Percepções sobre o racismo}

Os entrevistados citaram diversos aspectos negativos e as variadas consequências que o racismo pode trazer consigo no processo saúde e doença.

"Eu acho que já fui tratado mal em hospitais tanto pela doença quando pela cor, várias vezes" E7

"Discriminação é em relação a cor do racismo te tratam diferente por que você é diferente, magro, fraco" E10

Bailey (2017) em seu estudo sobre racismo estrutural e inequidades nos serviços de saúde, mostrou que bairros com predominância de pessoas negras tem menor qualidade no atendimento à saúde, além de piores profissionais se comparados a regiões onde residem pessoas de cor branca. Esse mesmo estudo demonstrou que, quando as pessoas negras buscavam atendimento em regiões com predominância de pessoas de cor branca, eram discriminadas e obtinham atendimento superficial se comparadas as outras pessoas.

Categoria Temática 2 - Consequências e efeitos do racismo

Nessa categoria, os entrevistados citaram diversos aspectos negativos e as variadas consequências que o racismo pode trazer consigo no processo saúde e doença. A piora da saúde física foi uma das queixas mais relevantes entre as falas desses indivíduos.

"Eu acho que isso atrapalha minha saúde sim de forma muito negativa por que a pessoa não sabe os problemas que eu tenho é isso piorar minha dor" E10 
"Se eu for destratado eu vou me excluir e não vou contar para ninguém, então vai aumentar minhas dores" E3

Diversos estudos demonstram as repercussões étnicas e raciais na saúde da população. Shavers (2006) mostrou que as percepções individuais de experiências com a discriminação racial têm sido associadas a um maior número de comportamentos e resultados adversos à saúde, incluindo piora da saúde física e mental. Em um estudo, Edwards (2008) identificou que a experiência de vida de discriminação racial foi o mais forte preditor de causas de dor nas costas e fatores relacionados com a saúde mental em uma amostra dos afro-americanos. Similarmente, Burgess et al (2009) encontrou que a percepção de discriminação racial foi associada com maior dor corporal em uma amostra de idosos afro-americanos.

Categoria Temática 3 - Enfrentamento do racismo pelas pessoas com DF

Os entrevistados apesar de terem suas emoções e comportamentos prejudicados pelas experiências racistas, as expressões dos mesmos, concomitantemente, se mostraram como uma forma de enfrentamento por parte dessas pessoas a todo esse processo excludente e discriminatório que elas sofrem.

"No momento que eu sofrer o racismo eu vou me sentir excluido, no momento eu vou criar raiva por causa desse racismo, ficar magoado"E3

"Se eu fosse discriminada isso iria afetar muito minha saúde ia ficar deprimida, muito decepcionada por que alguém me discriminou eu ia ficar nervosa"E6

Bogart (2016) em seu estudo sobre as formas de enfrentamento que homens negros soropositivos mostrou que, através das narrativas, a principal estratégia de enfrentamento relatada foi evitar, que incluiu o uso de comportamentos, cognições e emoções para parar de pensar sobre a discriminação relacionada ao estressor em si, ou dos efeitos disso. A evasão foi mais usada para combater discriminação racial e as formas como a evasão manifestada como uma estratégia de enfrentamento diferiu por identidade. A prevenção pode ser tanto reativa (respostas imediatas de um evento de discriminação), bem como pró-ativa (evitando comportamentalmente situações em que a discriminação foi antecipada / foi experimentada anteriormente).

\section{CONSIDERAÇÕES FINAIS (ou Conclusão)}

Esse estudo permite compreender como as pessoas com DF percebem as experiências racistas nas práticas de cuidado à saúde.

Quando se aborda a questão da percepção das experiências discriminatórias conclui-se que essas pessoas, apesar do racismo muitas vezes estar velado nos serviços de saúde, percebem esse fenômeno e conseguem na maioria das vezes mensurar o quanto pode ser prejudicial em suas vidas.

As pessoas com DF também demonstram formas de enfrentamento que elas possuem diante das práticas racistas vivencias pelas mesmas. Formas essas que se mostram como um fenômeno de autoproteção que na maioria das vezes é a única forma que elas encontram para lidar com essas experiências.

Diante do contexto estudado cabe a nós, estudantes e profissionais de saúde disseminar o conhecimento sobre a DF e também ser agentes ativos contra as limitações que o 
sistema de saúde impõe a essas pessoas e também contra todo e qualquer processo de discriminação que elas possam sofrer.

\section{REFERÊNCIAS}

BARDIN, L. Análise de conteúdo. Lisboa, Portugal: Edições 70, 2009.

BAILEY, Z; Structural racism and health inequities in the USA: evidence and interventions.

Lancet 2017; 389: 1453-63

BASTOS J.L.; FAERSTEIN E; CELESTE R.K; BARROS A.J;. Explicit discrimination and health: development and psychometric properties of an assessment instrument. Rev Saude Publica. 2012;46:269-78

BOGART, L.; Culture, Health \& Sexuality An International Journal for Research, Intervention and Care. SN: 1369-1058 (Print) 1464-5351 (Online) Journal homepage: http://www.tandfonline.com/loi/tchs20

BRASIL. Ministério da Saúde, Secretaria de Atenção à Saúde. Doença falciforme: condutas básicas para tratamento. Secretaria de Atenção à Saúde, Departamento de Atenção Especializada. Brasília: Ministério da Saúde; 2001. 64p.

PRIEST N.; A systematic review of studies examining the relationship between reported racism and health and wellbeing for children and young people. Soc Sci Med. 2013;95:11527. Epub 2012 Dec 19

SHAVERS V.L.;The state of research on racial/ethnic discrimination in the receipt of health care. Am J Public Health 2012;102:953-966.

SOARES, E. P. B. Cuidar de pessoas com doença falciforme na unidade de emergência: discurso de uma equipe multiprofissional. DOI: 10.4025/cienccuidsaude.v13i2.19505, 2014 